Jurnal Geocelebes Vol. 2 No. 1, April 2018, 31 - 35

\title{
KARAKTERISASI SERPIH PADA FORMASI TALANGAKAR SEBAGAI POTENSI SHALE HYDROCARBON
}

\author{
Jamaluddin $^{1^{*}}$, Muh. Fawzy Ismullah Massinai ${ }^{2}$, Erfan Syamsuddin ${ }^{2}$ \\ ${ }^{I}$ China University of Petroleum, Eart China \\ ${ }^{2}$ Program Studi Geofisika, FMIPA Universitas Hasanuddin, Makassar, Indonesia \\ *Penulis koresponden. Alamat email: jamaljamaluddin1994@yahoo.com
}

\begin{abstract}
Abstrak
Eksplorasi dan eksploitasi di Indonesia saat ini masih terfokus pada energi konvensional hidrokarbon dibandingkan energi nonkonvensional hidrokarbon seperti gas serpih. Gas serpih adalah salah satu energi nonkonvensional yang kaya material organic dan mencapai kematangan, pada kondisi dan tipe tertentu mampu berfungsi sebagai reservoir minyak dan gas. Jendela awal kematangan pada kedalaman 1200-2200 m dan kategori tipe kerogen II/III menghasilkan minyak dan gas.
\end{abstract}

Kata kunci: Formasi Talangakar, Material Organik, Shale Hidrokarbon

\begin{abstract}
Exploration and exploitation in Indonesia currently still focused on conventional hydrocarbon energy than the energy of the nonconventional hydrocarbons such as shale gas. Shale gas is one of the energy rich organic material nonconventional and reach maturity, on the conditions and certain types are capable of functioning as a reservoir of oil and gas. The initial maturity of the window at a depth of $1200-2200 \mathrm{~m}$ and category II/III kerogen type produces oil and gas.
\end{abstract}

Key Words: Organic Material, Shale Hydrocarbon, Talangakar Formation

\section{Pendahuluan}

Kebutuhan minyak dan gas bumi dari sumber energi fosil di Indonesia semakin lama semakin meningkat, sedangkan cadangan migas yang dihasilkan dari reservoir konvensional semakin berkurang. Untuk mengantisipasi kekurangan gas, diperlukan eksplorasi akan sumber daya baru (unconventional resources), salah satunya adalah shale gas.

Formasi Batuan yang dijadikan fokus pada penelitian ini adalah Formasi Talang Akar. Formasi ini didominasi oleh batupasir pada bagian bawah dan batulempung pada bagian atasnya. Batulempung ini berfungsi sebagai batuan induk karena memiliki kandungan organik totalnya yang cukup. Secara kematangan, formasi Talang Akar di lokasi ini sudah masuk ke daerah dry gas window dengan Ro > 1.4\% pada Top Talang Akarnya padahal kedalamnya baru mencapat 4995 ftmd. Dengan informasi seperti itu kemungkinan dulunya lokasi ini pernah berada di daerah dalaman kemudian terjadi pengangkatan sehingga daerah yang masuk dry gas window tersebut menjadi relatif lebih dangkal.

Formasi Talangakar diendapkan secara tidak selaras di atas Formasi Lahat. Formasi ini diendapkan secara tidak selaras di atas Formasi Lahat. Formasi ini 
dibagi menjadi 2 anggota yakni GRM (grit sand member) yang tersusun oleh klastika kasar dengan sisipan serpih dan batubara serta angoota TRM (transitional member) yang terdapat shale.

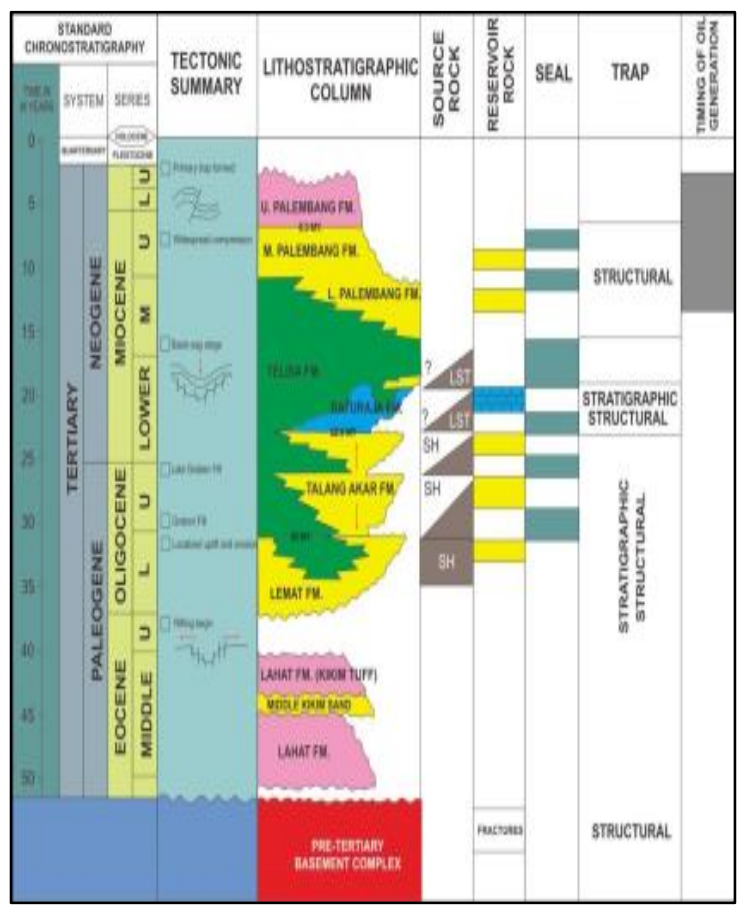

Gambar 1. Stratigrafi Cekungan Sumatera Selatan (De Coster, 1974).

Lingkungan pengendapan Formasi Talang Akar berada di lingkungan litoral hingga shallow marine yang berumur Oligosen Akhir - Miosen Awal.Ketebalan formasi bervariasi antara $100-500$ meter. sedangkan kontak antara Formasi Talang Akar dengan Telisa dan anggota Basal Batugamping Telisa adalah conformable. Kontak antara Talang Akar dan Telisa sulit di pick dari sumur di daerah palung disebabkan litologi dari dua formasi ini secara umum sama.

\section{Metode Penelitian}

Analisis pirolisis dilakukan terhadap perconto yang mempunyai kandungan TOC lebih besar atau sama dengan $0.5 \%$. Analisis dilakukan terhadap perconto yang telah digerus halus seberat kurang lebih $100 \mathrm{mg}$ dengan menggunakan alat Rock Eval-5. Tujuan analisis ini adalah untuk mengetahui kuantitas minyak bumi atau hidrokarbon bebas $\left(\mathrm{S}_{1}\right)$, dan kuantitas kerogen $\left(S_{2}\right)$ yang keduanya dinyatakan dalam $\mathrm{kg} / \mathrm{ton}$ dan temperature maksimum $\left(\mathrm{T}_{\text {maks }},{ }^{\circ} \mathrm{C}\right)$ yaitu temperature puncak pada saat $\mathrm{S}_{2}$ pecah. Data HI bila diplot terhadap $\mathrm{T}_{\text {maks }}$ (Diagram Van Krevelen) akan memberikan indikasi umum kualitas (tipe) kerogen dan jenis material yang dhasilkan, minyak atau gas.

\section{Hasil dan Pembahasan}

Penentuan kematangan termal sedimen dari sumur A-1 dilakukan dengan metode pengamatan mikroskopis melalui analisis pantulan vitrinit (VR) dan indeks warna spora (SCI). Data hasil pengukuran pantulan vitrinit maupun indeks warna spora menunjukkan hasil yang cukup baik dari segi kuantitas maupun kualitasnya sehingga layak untuk dipergunakan. Kedalaman sumur menunjukkan bahwa interval di atas $1200 \mathrm{~m}$ masih berada pada tingkat belum matang (Immature) $\left(\mathrm{R}_{\mathrm{o}}<0.35 \%\right)$, interval antara $1200-2200 \mathrm{~m}$ pada tingkat awal matang (early mature) $\left(0.35<\mathrm{R}_{0}<0.6 \%\right)$, dan interval di bawah $2200 \mathrm{~m}$ pada tingkat matang (mature) secara termal dengan $\mathrm{R}_{\mathrm{o}}>0.6 \%$ (Peters, 1994).

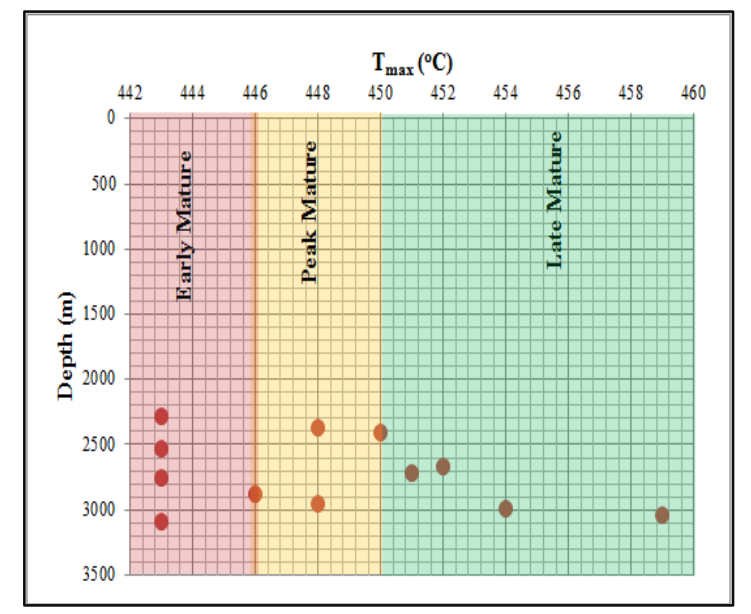

Gambar 2. Plot silang antara nilai $\mathrm{T}_{\text {maks }}$ terhadap kedalaman.

Penentuan tipe atau kualitas kerogen terhadap sedimen dari Formasi Talangakar dilakukan dengan menggunakan data pengamatan mikroskopis yang berupa komposisi kerogen dan kombinasi antara 
$\mathrm{T}_{\text {maks }}$ dengan Indeks Hidrogen. Dari data pengamatan mikroskopis terlihat bahwa kerogen yang terkandung di dalam serpih teranalisis sebagian besar didominasi oleh bahan organic humik-vitrinitik asal tumbuhan darat. Meskipun demikian, nilai HI sedimen teranalisa menunjukkan nilai tertinggi pada serpih di kedalaman $2885 \mathrm{~m}$ $(\mathrm{HI}=336)$ yang memberikan indikasi adanya kerogen liptinitik (Tipe II) dengan kapasitas sebagai pembentuk minyak. Serpih yang lain dari Formasi Talangakar teranalisis pada umumnya mengandung kerogen Vitrinitik (Tipe III) yang ditunjukkan oleh nilai HI antara 112 dan 190 dan mempunyai potensi optimum penghasil gas atau kondesat.

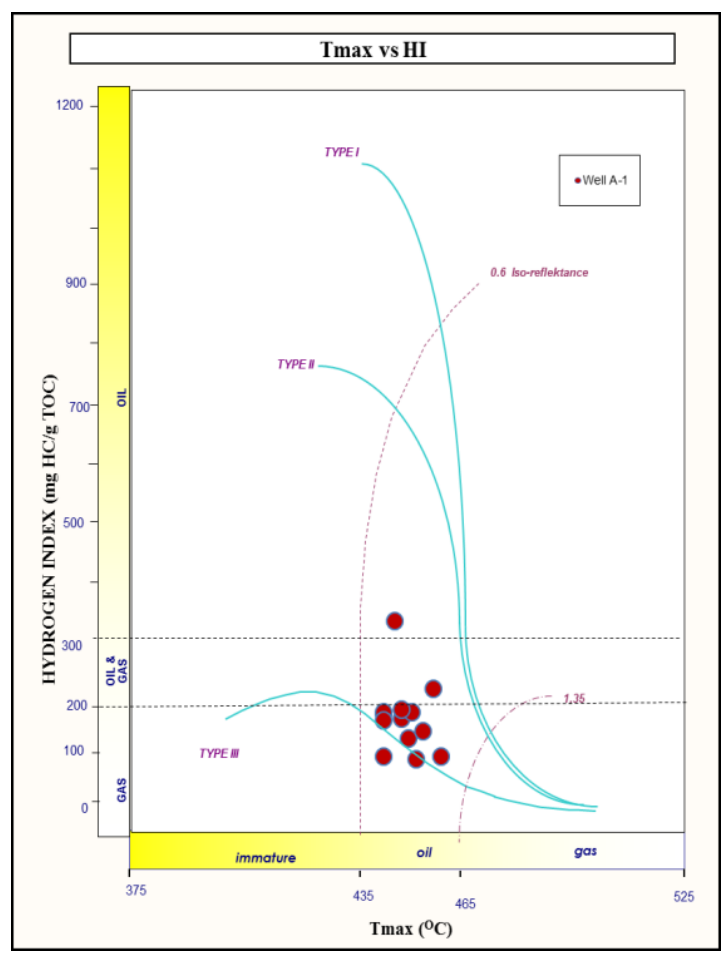

Gambar 3. Diagram Van Krevelen

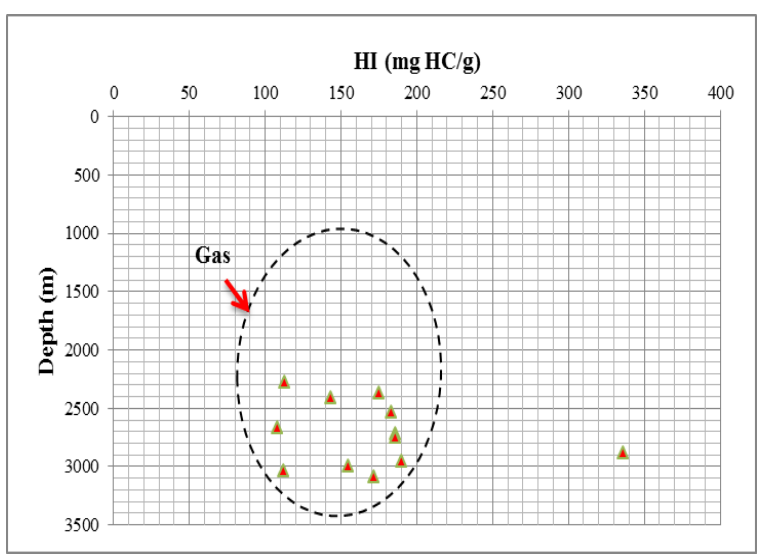

Gambar 4. Plot silang antara nilai $\mathrm{T}_{\text {maks }}$ terhadap kedalaman.

Sumur A-1 dominan mengandung gas pada kedalaman 2280-3085 m. Komposisi kerogen juga dipengaruhi oleh proses pemtngan terml, yaitu katagenesis dan metagenesis, yang mengubah kerogen tersebut. Pemanasan bawah permukaan menyebabkan reaksi-reaksi kimia yang memecah fragmen kecil kerogen menjadi minyak. Kerogen sisa juga mengalami perubahan yang tercermin dalam kondisi kimia dan fisikanya. Sejarah diagenesis dan katagenesis kerogen serta kondisi alamiah material organik penyusunnya sangat mempengaruhi kemampuan kerogen memproduksi minyak dan gas.

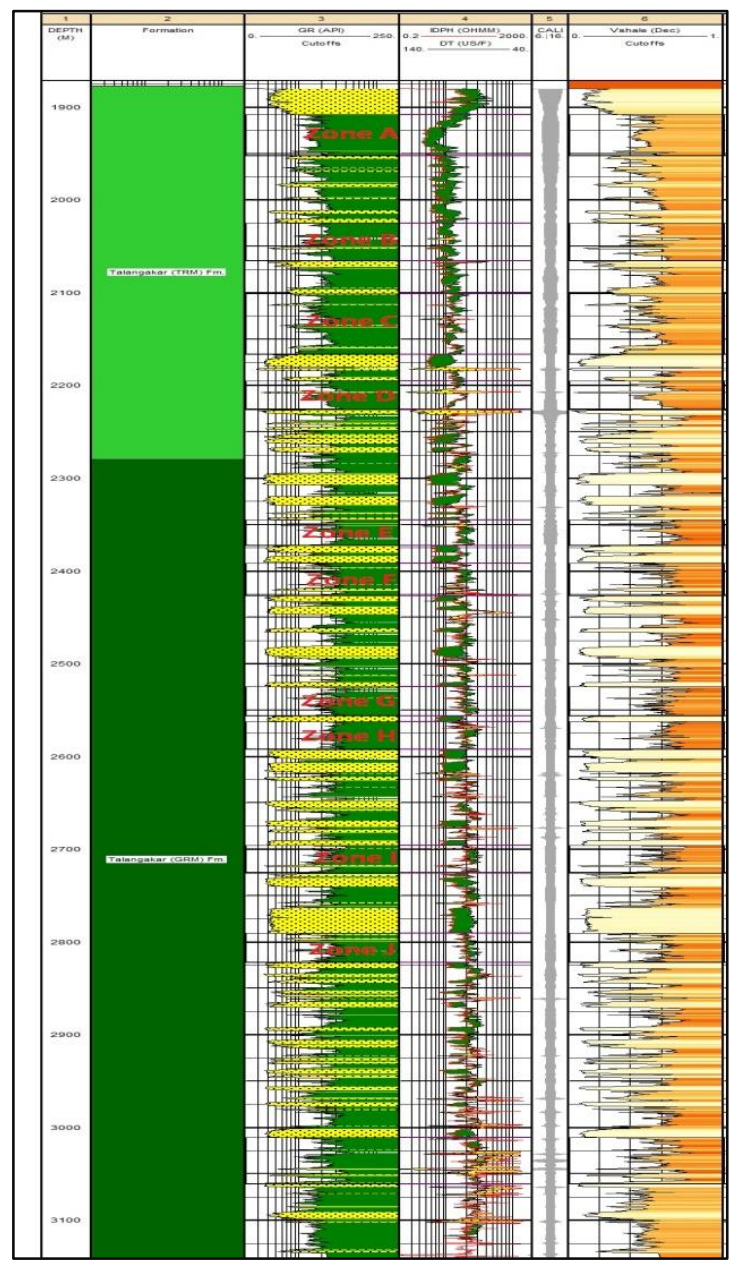

Gambar 5. Zona interest penelitian

Contoh batuan untuk analisis laboratorium merupakan batuserpih dengan ciri litologi: warna abu-abu hitam sedang, tingkat kekerasan lunak sampai setengah keras, 
memiliki tekstur blocky dan slately. Selain batuserpih, juga dilakukan pengambilan contoh dan analisis laboratorium untuk batulempung dengan ciri fisik: warna setengah abu-abu, dengan tingkat kekerasan keras sampai sangat keras, memiliki tekstur masif.

Formasi Talangakar menutupi Formasi Lemat dan batuan dasar. Susunan lapisannya terdiri terutama dari endapan fluvial dan delta. Adapun bagian atasnya terdiri dari dari serpih, lempung, pasir, dan sisipan-sisipan batubara yang kaya dengan pirit, glaukonit, dan foraminifera.
Nilai kandungan material organik di Formasi Talangakar berkisar antara 1,23$1,66 \%$. Hal ini mengindikasikan bahwa potensi Formasi Talangakar sebagai batuan induk adalah cukup berpotensi untuk menghasilkan hidrokarbon.

Di Cekungan Sumatra Selatan, menurut beberapa peneliti seperti diuraikan oleh Ginger (2005) menyebutkan bahwa nilai TOC Talang Akar bagian Atas bervariasi mencapai $36 \%$ dengan nilai Hydrogen Index (HI) antara 200 dan $350 \mathrm{mgHC} / \mathrm{g}$.

Tabel 1. Data kematangan dan komposisi kerogen daerah penelitian.

\begin{tabular}{|c|c|c|c|c|c|}
\hline $\begin{array}{c}\text { Kedalaman } \\
\text { (Meter) }\end{array}$ & Formasi & $\begin{array}{c}\text { Tmaks } \\
\left({ }^{\circ} \mathrm{C}\right)\end{array}$ & $\begin{array}{c}\mathrm{HI} \\
(\mathrm{mg} / \mathrm{g})\end{array}$ & $\begin{array}{c}\text { VR } \\
(\% \text { Ro })\end{array}$ & $\begin{array}{c}\text { SCI } \\
(1-10)\end{array}$ \\
\hline 2280 & \multirow{13}{*}{ Talang Akar } & 443 & 113 & 0.6 & 5.6 \\
\hline 2365 & & 448 & 175 & & 6.1 \\
\hline 2410 & & 450 & 143 & 0.59 & \\
\hline 2530 & & 443 & 183 & & 6 \\
\hline 2665 & & 452 & 108 & 0.65 & \\
\hline 2722 & & 451 & 186 & & 5.9 \\
\hline 2750 & & 443 & 186 & & 6.1 \\
\hline 2885 & & 446 & 336 & 0.65 & 5.9 \\
\hline 2952 & & 448 & 190 & 0.66 & \\
\hline 2994 & & 454 & 155 & 0.86 & \\
\hline 3040 & & 459 & 112 & & \\
\hline 3085 & & 443 & 172 & 0.95 & 6.6 \\
\hline 3105 & & 457 & 225 & 0.96 & 6.2 \\
\hline
\end{tabular}

\section{Kesimpulan}

Berdasarkan hasil penelitian dapat disimpulkan bahwa:

1. Tipe Bahan Organik, batuan sedimen mengandung hidrogen yang umumnya mencerminkan bahwa kerogen terkandung pada batuan Formasi Talangakar adalah tipe II dan tipe III dengan kapasitas cenderung menghasilkan gas.

2. Tingkat Kematangan Termal sedimen dari Formasi Talangakar yang dianalisis tingkat puncak matang (peak mature), Ro ratarata sampel $0,74 \%$.
3. Batuserpih dan batulempung daerah penelitian memiliki kandungan material organik yang cukup (fair) untuk dapat menjadi batuan sumber yang baik bagi pembentukan hidrokarbon.

4. Nilai kandungan material organic di Formasi Talangakar berkisar antara 1,23 - 1,66\%. Hal ini mengindikasikan bahwa potensi Formasi Talangakar sebagai batuan induk adalah cukup berpotensi untuk menghasilkan hidrokarbon. 


\section{Daftar Pustaka}

De Coster, G.L.. 1974. The geology of the Central and South Sumatra: Proceedings Indonesian Petroleum Association 3rd Annual Convention, Jakarta, Indonesia, p. 77-110.

Ginger, D., Fielding, K., 2005. The Petroleum Systems and Future Potential of The South Sumatra Basin, Proceedings, Indonesian Petroleum Association, Thirtieth Annual Convention \& Exhibition.
Peters, K.E., Cassa M.R., 1994, Applied Source Rock Geochemistry, AAPG Memoir 60: The Petroleum System from Source to Trap

Van Krevelen, D.W., 1961. Coal. Elsevier, New York. In: The Biomarker Guide, Biomarkers and Isotopes in the Environment and Human History Vol.1, Cambridge University Press, 72- 156 